\title{
Influence of Physical Properties of Biomaterials on Cellular Behavior
}

\author{
Susan Lin • Nivedita Sangaj • Tojo Razafiarison • Chao Zhang • Shyni Varghese
}

Received: 25 August 2010 / Accepted: 19 January 2011 / Published online: 18 February 2011

(C) The Author(s) 2011. This article is published with open access at Springerlink.com

\begin{abstract}
Purpose In this study, we evaluated the effect of hydrogel structural properties on proliferation and biosynthesis activity of encapsulated chondrocytes.

Methods Hydrogels with varying structural and mechanical properties were prepared by photopolymerizing PEGDA precursors having MWs of $3.4 \mathrm{kDa}, 6 \mathrm{kDa}, 10 \mathrm{kDa}$, and $20 \mathrm{kDa}$ and were characterized for their swelling ratio, network structure, morphology, and mechanical properties. The effect of hydrogel structural properties on the cellular activity of encapsulated chondrocytes was studied over four weeks.

Results Varying the molecular weight of PEGDA precursors exhibited a significant effect on the structural and mechanical properties of the hydrogels. Large mesh size was found to support cell proliferation. However, extracellular matrix (ECM) accumulation varied with the precursor molecular weight. Both PEGDA $6 \mathrm{kDa}$ and $10 \mathrm{kDa}$ hydrogels supported GAG accumulation, while PEGDA $10 \mathrm{kDa}$ and 20KDa hydrogels supported collagen accumulation. Chondrocytes cultured in PEGDA $10 \mathrm{kDa}$ hydrogels expressed a relative increase in collagen type II and aggrecan expression while maintaining low collagen type I expression.
\end{abstract}

Conclusions Increasing mesh size of the hydrogels resulted in an increase in cellular proliferation exhibiting the strong correlation between mesh size and cell growth, while mesh size had a differential effect on ECM accumulation and expression of cartilage specific markers.

Electronic Supplementary Material The online version of this article (doi: | 0. I 007/s | | 095-0 I I-0378-9) contains supplementary material, which is available to authorized users.

S. Lin · N. Sangaj · T. Razafiarison $\cdot$ C. Zhang $\cdot S$. Varghese $(\bowtie)$ Department of Bioengineering, University of California, San Diego 9500 Gilman Drive

La Jolla, California 92093-0412, USA

e-mail: svarghese@ucsd.edu
KEY WORDS cartilage · chondrocytes · collagen · GAG . mesh size $\cdot$ scaffold

$\begin{array}{ll}\text { ABBREVIATIONS } \\ \text { ECM } & \text { extracellular matrix } \\ \text { GAG } & \text { glycosaminoglycan } \\ \text { PEG } & \text { poly(ethylene glycol) } \\ \text { SR } & \text { swelling ratio } \\ \bar{M}_{C} & \text { average molecular weight between two adjacent } \\ & \text { crosslinks } \\ \xi & \text { mesh size }\end{array}$

\section{INTRODUCTION}

Tissue engineering has been touted to play an important role in regenerating functional biological replacements for dysfunctional tissues. Both scaffolds and cells have been shown to play a crucial role in regenerating tissues that emulate structural and functional characteristics of native tissues. Hydrogels are considered as a preferred scaffold for cartilage tissue engineering due to their structural similarities and enhanced mass transport abilities. Photopolymerized poly(ethylene glycol) (PEG) hydrogels have been extensively studied for cartilage tissue regeneration where polymerization of PEG-diacrylate (PEGDA) precursors allows embedment of cells within the crosslinked network $(1-4)$. The resulting three-dimensional network is known to support synthesis of cartilage-specific extracellular matrix (ECM) components such as sulfated glycosaminoglycan (GAG) and type II collagen of encapsulated chondrocytes (2).

A number of studies have evaluated the effect of chemical, structural, and mechanical properties of 
hydrogels on cellular responses such as growth, migration, and biosynthetic activity (5-10). A commonly used approach for varying structural and chemical properties of hydrogels is by changing the crosslink density, which can be achieved through varying the amounts of crosslinker, precursor concentration, and/or molecular weight of the precursor. These changes in crosslink density in turn dictate network mesh size due to the inverse relationship of the crosslink density and the network mesh size.

Network mesh size is a key component in governing mass transfer and is used to correlate the diffusivity of molecules in hydrogels. It has been shown that network mesh size of hydrogel plays a critical role in modulating the cellular phenotype, proliferation, and extracellular matrix (ECM) production (2,11-15). Studies have also shown the significant role of network mesh size on the spatial distribution of ECM for functioning cartilage tissue $(16,17)$. For example, Bryant et al. varied hydrogel mesh size by using different precursor concentrations and showed that increasing the mesh size results in an increase in collagen content, while the GAG content remained unchanged (18). However, the distribution of GAG as observed in Safranin-O staining was uniform in hydrogels with higher mesh size (low crosslink density) as compared to the localized distribution observed in hydrogels with lower mesh size (i.e., highly crosslinked hydrogels) (18).

In this study, we examined the effect of network mesh size on the response of encapsulated chondrocytes in terms of their proliferation and accumulation of ECM over four weeks. PEG hydrogels with varying structural and mechanical properties have been created by varying the molecular weight of the PEG precursor. PEG-based hydrogels are used as a model system due to their amenability to fine-tune the crosslink network and their bioinertness, thereby eliminating any biological effect of the matrix.

\section{MATERIALS AND METHODS}

\section{Isolation of Chondrocytes}

Chondrocytes were isolated from articular cartilage of 2-4-week-old calf following the previously reported method (12). Briefly, chondrocytes were isolated by incubating cartilage pieces in high glucose Dulbecco's modified Eagle medium (DMEM) (GIBCO) containing 5\% fetal bovine serum (FBS) (Atlanta Biologicals, GA) and 0.2\% collagenase (Worthington Biochemical Corp., NJ) for $16 \mathrm{~h}$ at $37^{\circ} \mathrm{C}$ and $5 \% \mathrm{CO}_{2}$. The resultant cell suspension was filtered through a $70 \mu \mathrm{m}$ nylon mesh, and the cells were washed with phosphate-buffered saline (PBS) containing $100 \mathrm{U} / \mathrm{mL}$ of penicillin and $100 \mu \mathrm{g} / \mathrm{mL}$ of streptomycin (pen-strep) (GIBCO).

\section{Synthesis of PEGDA Precursors}

PEGDA was synthesized by reacting acryloyl chloride with hydroxyl end groups of PEG using the reported method (19). Briefly, $3 \mathrm{mmol}$ of PEG was transferred to a roundbottom flask containing $500 \mathrm{~mL}$ of toluene and refluxed in an oil bath for azeotropic removal of traces of water. On cooling this solution to room temperature, $12 \mathrm{mmol}$ of triethyl amine was added with vigorous stirring. Twelve mmol of acryloyl chloride in $15 \mathrm{~mL}$ anhydrous tetrahydrofuran was added to this reactant mixture drop-wise for $30 \mathrm{~min}$ in icebath. The content was then heated at $45^{\circ} \mathrm{C}$ in oil bath overnight. Quaternary ammonium salt formed was removed by filtering the solution through a bed of diatomaceous earth. The filtrate was concentrated on a rotary evaporator and precipitated in diethyl ether. Precipitated product was re-dissolved in dichloromethane and reprecipitated in diethyl ether. Resultant PEGDA precursor was column-purified and dialyzed against deionized water followed by lyophilization before use. PEGDA with molecular weights of 3,400 Da (PEGDA-3.4 k), 6,000 Da (PEGDA6 k), 10,000 Da (PEGDA-10 k), and 20,000 Da (PEGDA$20 \mathrm{k}$ ) were used for this study. Dialysis tubing (Spectrum Labs Inc., USA) with a molecular weight cut-off (MWCO) of 500 Da was used for PEGDA-3.4 k, - 6 k and - 10 k, while for PEGDA-20 k, a dialysis tube with a MWCO of 12,000 Da was used.

\section{Photopolymerization and Chondrocyte Encapsulation}

For photopolymerization, a $10 \%(\mathrm{w} / \mathrm{v})$ solution of PEGDA in PBS was mixed with $0.05 \%(\mathrm{w} / \mathrm{v})$ photoinitiator Irgacure 2959 (CIBA Speciality Chemicals, USA) used as 10\% (w/v) solution in $70 \%$ ethanol. The polymer solution was transferred to cylindrical molds (having dimensions of $6.5 \mathrm{~mm}$ diameter and $4 \mathrm{~mm}$ height) and exposed to $365 \mathrm{~nm}$ UV radiation for $5 \mathrm{~min}$. For cell encapsulation, primary chondrocytes were dispersed in sterile polymer solution to yield a final cell density of $20 \times 10^{6}$ cells $/ \mathrm{mL}$. Resulting cell-laden constructs were transferred to a 24-well plate and cultured in chondrocyte medium.

\section{Swelling Ratio and Determination of Mesh Size}

Swelling ratios of the acellular hydrogels were determined using gravimetric method. Hydrogels were thoroughly washed and swelled in PBS, then dried at $40^{\circ} \mathrm{C}$ under vacuum until a constant weight was obtained. Dried gels were re-immersed in $\mathrm{PBS}$ at $37^{\circ} \mathrm{C}$, and the weight of swollen hydrogels was measured in an equilibrium-swollen 
state. Swelling ratio was calculated by using the following formula: $\mathrm{SR}=\mathrm{W}_{\mathrm{s}} / \mathrm{W}_{0}$, where $\mathrm{W}_{0}$ and $\mathrm{W}_{\mathrm{s}}$ are weights of hydrogel before and after swelling, respectively. The average and standard deviation of triplicate samples was calculated.

The average molecular weight between the two adjacent crosslinks $\left(\bar{M}_{c}\right)$ was determined using the Peppas-Merrill model following formfula given below (20):

$\frac{1}{\overline{M_{c}}}=\frac{2}{\overline{M_{n}}}-\frac{\left(\frac{\bar{v}}{V_{1}}\right)\left[\ln \left(1-v_{2, s}\right)+v_{2, s}+\chi_{1} v_{2, s}^{2}\right]}{v_{2, r}\left[\left(\frac{v_{2, s}}{v_{2, r}}\right)^{\frac{1}{3}}-\frac{1}{2}\left(\frac{v_{2, s}}{v_{2, r}}\right)\right]}$

where $\bar{M}_{n}$ is the average molecular weight of PEG oligomers, $\bar{M}_{c}$ is the average molecular weight between two adjacent crosslinks, $v_{2, s}$ is the polymer volume fraction in the swollen state, $\chi_{1}$ is the Flory-Huggin's polymer-solvent interaction parameter ( 0.426 for PEG-water system), $\bar{v}$ is the specific volume of PEGDA in its amorphous state $\left(0.893 \mathrm{~cm}^{3} / \mathrm{g}\right), \mathrm{V}_{1}$ is the molar volume of the solvent $\left(18 \mathrm{~cm}^{3} / \mathrm{mol}\right.$ for water), and $v_{2, r}$ is the polymer fraction in the gel $(0.1)$.

Mesh size $(\xi)$ of the hydrogel is calculated by using the following formula (20):

$\xi=\left(\overline{r_{0}^{2}}\right)^{1 / 2} v_{2, s}^{-1 / 3}$

$\left(\overline{r_{0}^{2}}\right)=l^{2}\left[2 \frac{\bar{M}_{c}}{M_{r}}\right] C_{n}$

where $\left[r_{0}^{2}\right]^{1 / 2}$ is the root mean square end-to-end distance of the polymer in its free state, $l$ is the carbon-carbon bond length $(0.154 \mathrm{~nm}), \mathrm{C}_{\mathrm{n}}$ is the rigidity factor of polymer (4 for PEG), and $M_{r}$ is the molecular weight of repeating units (44 g/mol for PEG).

\section{Scanning Electron Microscopy (SEM)}

The morphology and internal structure of the hydrogels were examined using scanning electron microscope (SEM, Philips XL30 ESEM). The equilibrium-swollen hydrogel samples were frozen in liquid nitrogen and immediately fractured. The fractured samples were lyophilized and finally sputter-coated with gold for $40 \mathrm{~s}$ by using Emitech K575X sputter coater.

\section{Mechanical Properties}

Mechanical properties of the hydrogels, such as compressive modulus, ultimate strength, and strain at break, were determined in their equilibrium-swollen state using the Instron 3342 Universal Testing system (Instron, Norwood,
MA, USA) equipped with model 2519-004 force transducer. Cylindrical hydrogels with height and diameter of $7 \mathrm{~mm}$ and $8 \mathrm{~mm}$, respectively, were used for testing. The maximum force load was $250 \mathrm{~N}$, and the crosshead speed was $10 \mathrm{~mm} / \mathrm{min}$. Compressive modulus of the hydrogel was determined as the slope of the initial linear region of the stress-strain curve. Average and standard deviation of quadruplicate samples are reported.

\section{Chondrocyte Culture}

Chondrocyte medium was prepared by adding 10\% FBS, $1 \mathrm{mM}$ sodium pyruvate (GIBCO), $10 \mathrm{mM}$ HEPES (GIBCO), $0.1 \mathrm{mM}$ minimal essential medium with nonessential amino acids (GIBCO), $0.4 \mathrm{mM}$ proline (Sigma), $50 \mathrm{mg} / \mathrm{L}$ vitamin $\mathrm{C}$ (Sigma), $100 \mathrm{U} / \mathrm{ml}$ of penicillin and $100 \mu \mathrm{g} / \mathrm{mL}$ of streptomycin to high glucose DMEM. The cell-laden hydrogels (hereafter referred to as constructs) were incubated at $37^{\circ} \mathrm{C}$ in humidified $5 \% \mathrm{CO}_{2}$ atmosphere for four weeks. The medium was changed twice a week.

\section{Live-Dead Assay}

The cell viability of encapsulated chondrocytes was determined $24 \mathrm{~h}$ after encapsulation by using live/dead assay kit (Molecular Probes, Eugene, OR) following manufacturer's protocol. Briefly, constructs sliced into thin sections were washed with PBS and incubated in a solution of $0.5 \mu \mathrm{L}$ of Calcein AM and $2 \mu \mathrm{L}$ of ethidium homodimer- 1 in $1 \mathrm{~mL}$ DMEM. After an incubation of $30 \mathrm{~min}$, the sections were rinsed with $\mathrm{PBS}$, and the images were taken by using the Zeiss Observer Al fluorescence microscope equipped with an X-Cite 120 (EXFO) mercury lamp.

\section{Biochemical Assay}

Constructs for biochemical assays were dried using a lyophilizer, and their dry weights were measured. Glycosaminoglycan (GAG), collagen, and deoxyribonucleic acid (DNA) contents were determined by using previously reported methods (21). Dried samples were digested with $1 \mathrm{~mL}$ papain solution $(125 \mu \mathrm{g} / \mathrm{mL})$ Worthington Biochemical Corp., NJ) in PBE buffer at $60^{\circ} \mathrm{C}$ for $16 \mathrm{~h}$.

DNA content of the papain digested samples was determined using Quant-iT PicoGreen dsDNA reagent (Molecular Probes). After incubation with the reagent, the fluorescence intensity was measured at an excitation wavelength of $480 \mathrm{~nm}$ and an emission wavelength of $520 \mathrm{~nm}$. GAG content was measured using 1, 9dimethylmethylene blue (DMMB) spectroscopic assay at $525 \mathrm{~nm}$ with chondroitin sulfate as a standard (22). For determination of collagen content, the papain digest was acid hydrolyzed and reacted with chloramine- $\mathrm{T}$ followed 
by p-dimethylaminobenzaldehyde (23). The collagen content was measured spectroscopically as hydroxyproline content at $550 \mathrm{~nm}$. The conversion factor of 7.6 was used to convert the hydroxyproline to collagen content (24).

Histological and Immunofluorescent Assays. For histological and immunofluorescent assays, the constructs after four weeks of culture were fixed with 4\% paraformaldehyde, embedded in optimum cutting temperature (OCT) compound (Ted Pella Inc, CA), and cryosectioned at $20 \mu \mathrm{m}$ thickness. Safranin-O staining for proteoglycans was visualized using a microscope under bright field. Immunofluorescent staining for collagen type II was done by using polyclonal antibody 70R-CR008X (Fitzgerald Industries, MA) with final conjugation of bound antibody done by incubating with Alexa Fluor 488 goat antirabbit secondary antibody (Invitrogen, CA). Nuclei were stained with 4',6-diamidino-2-phenylindole (DAPI) solution (Vector Lab, CA).

\section{Gene Expression by Qrt-PCR}

Total RNA was isolated from the constructs using TRIzol and reverse transcribed into cDNA using iScript cDNA synthesis kit (Bio-Rad Laboratory). Real-time quantitative reverse transcription polymerase chain reaction (qRT-PCR) was performed using power SYBR green PCR master mix solution and the ABI Prism 7300 Sequence Detection System (Perkin Elmer/Applied Biosystems, Rotkreuz, Switzerland). The primers used for qRT-PCR are listed in Table 1. The gene expression values of samples at four weeks were normalized to respective expression values of $\beta$-actin, and further normalized to day 0 values for comparison. Relative gene expression is then calculated as fold induction.

\section{Statistical Analysis}

Material properties of acellular PEGDA hydrogels were analyzed by one-way analysis of variance (ANOVA). For statistical comparison of biochemical assays between four groups, two-way ANOVA was done with Bonferroni post hoc test to identify significant differences between various constructs at respective time points. Both types of analysis were done at a 'p' value of 0.05 .

\section{RESULTS}

\section{Material and Structural Properties of PEGDA Hydrogels}

The structural and mechanical properties of the hydrogels can be controlled by varying the molecular weight of
Table I qRT-PCR Primer Sequences

\begin{tabular}{|c|c|c|c|}
\hline Gene & $\begin{array}{l}\text { GenBank } \\
\text { Accession } \\
\text { No. }\end{array}$ & & Sequence \\
\hline \multirow[t]{2}{*}{$\begin{array}{l}\text { Collagen I } \\
(\text { la2) }\end{array}$} & \multirow[t]{2}{*}{ NMI74520 } & Forward & $\begin{array}{l}\text { 5'-TGA-GAG-AGG- } \\
\text { GGT-TGT-TGG-AC-3' }\end{array}$ \\
\hline & & Reverse & $\begin{array}{l}\text { 5'-AGG-TTC-ACC- } \\
\text { CTT-CAC-ACC-TG-3' }\end{array}$ \\
\hline \multirow[t]{2}{*}{$\begin{array}{l}\text { Collagen II } \\
(\text { Ila I) }\end{array}$} & \multirow[t]{2}{*}{$\times 02420$} & Forward & $\begin{array}{l}\text { 5'-CAC-TCT-AGG-ACT- } \\
\text { CTG-CAC-TGA-ATG-3' }\end{array}$ \\
\hline & & Reverse & $\begin{array}{l}\text { 5'-GGG-AGC-AAA-GTC- } \\
\text { CGA-ACT-GTG-3' }\end{array}$ \\
\hline \multirow[t]{2}{*}{ Aggrecan } & \multirow[t]{2}{*}{ U76615 } & Forward & $\begin{array}{l}\text { 5'-GAA-ACC-TCT-GGA- } \\
\text { CTC-TIT-GGT-GTC-3' }\end{array}$ \\
\hline & & Reverse & $\begin{array}{l}\text { 5'-GCC-AGA-TAT-TTC- } \\
\text { TCC-ATA-AAA-CCC- } \\
\text { TGA-3' }\end{array}$ \\
\hline \multirow[t]{2}{*}{$\beta$-actin } & \multirow[t]{2}{*}{ AYI4I970 } & Forward & $\begin{array}{l}\text { 5'-CTG-CGG-CAT-TCA- } \\
\text { CGA-AAC-TA-3' }\end{array}$ \\
\hline & & Reverse & $\begin{array}{l}\text { 5'-ACC-GTG-TTG-GCG- } \\
\text { TAG-AGG-TC-3' }\end{array}$ \\
\hline
\end{tabular}

the PEGDA precursor and/or changing the crosslinker and/or precursor concentration during polymerization. In this study, we altered the network mesh size by changing the molecular weight of PEGDA precursors from $3.4 \mathrm{kDa}$ to $20 \mathrm{kDa}$ while keeping the precursor concentration constant $(10 \%)$. The equilibrium swelling ratio, network mesh size $(\xi)$, and average molecular weight between the adjacent crosslinks $\left(\bar{M}_{c}\right)$ of these hydrogels are given in Table 2. Increasing the molecular weight of the PEGDA precursor exhibited an increase in swelling ratio of the hydrogel as measured at $37^{\circ} \mathrm{C}$, except for hydrogels synthesized from PEGDA-6 $\mathrm{k}$ versus PEGDA-10 k, which exhibited similar swelling behavior. The mesh size, calculated from equilibrium swelling ratios of the hydrogels, was found to increase from $4.5 \mathrm{~nm}$ to $13.08 \mathrm{~nm}$ with increasing molecular weight of PEGDA precursors from $3.4 \mathrm{kDa}$ to $20 \mathrm{kDa}$, respectively. Similarly, the $\bar{M}_{c}$ of the hydrogels increased with increasing the molecular weight of PEGDA precursor.

Figure 1 shows the SEM images of the corresponding freeze-dried hydrogels. As anticipated, the pore size of hydrogels was highly correlated with the precursor molecular weight. PEGDA-3.4 k hydrogels exhibited a pore size of 9-13 $\mu \mathrm{m}$, while those of PEGDA-20 k displayed a pore size of $38-42 \mu \mathrm{m}$.

Mechanical properties of hydrogels were measured in terms of compressive modulus, ultimate stress, and ultimate strain (Table 3). With reduction in the crosslink density or consequent increase in $\bar{M}_{c}$, the rigidity of the hydrogel was reduced as seen from the compressive modulus. However, 
Table $2 \mathrm{SR}, \bar{M}_{c}$, and $\xi$ of PEGDA Hydrogels Based on Precursors of Varying Molecular Weight

\begin{tabular}{lccr}
\hline Hydrogel & SR $(\%)$ & $\bar{M}_{c}(\mathrm{~g} / \mathrm{mol})$ & $\xi(\mathrm{nm})$ \\
\hline PEGDA- 3.4 k & $13.4(1.2)$ & $897.3(92)$ & $4.51(0.4)$ \\
PEGDA-6 k & $17.9(1.7)$ & $1,663.5(145)$ & $6.76(0.5)$ \\
PEGDA-10 k & $18.2(1.3)$ & $2,186.4(190.6)$ & $7.78(0.5)$ \\
PEGDA-20 k & $27.0(1.8)$ & $4754(348.9)$ & $13.09(0.8)$ \\
\hline
\end{tabular}

${ }^{a}$ Values in the parenthesis represent standard deviation.

Statistical analysis of swelling ratios of hydrogels showed that except for PEGDA-6 k-PEGDA- $10 \mathrm{k}$ pair, all the values were significantly different from each other.

ultimate strain and stress increased simultaneously, except for PEGDA- $6 \mathrm{k}$ and $-10 \mathrm{k}$, which exhibited similar ultimate strength. In fact, the ultimate compressive strength of PEGDA-20 k was about 42 times greater than PEGDA$3.4 \mathrm{k}$.

\section{Encapsulation of Chondrocytes and Chondrocyte Culture}

Previous studies have shown that PEG hydrogels support the encapsulation of chondrocytes and stem cells $(3,16,23)$. Chondrocytes were successfully encapsulated in $10 \%(\mathrm{w} / \mathrm{v})$ PEGDA hydrogels irrespective of their differences in precursor molecular weight at a cell density of 2 million cells per $100 \mu \mathrm{L}$ construct. The cell viability examined $24 \mathrm{~h}$ after encapsulation showed $74-80 \%$ live cells for all the hydrogels (Figure S1 in Supplementary Material). The cellladen hydrogels were cultured in chondrocyte medium and were evaluated for the effect of hydrogel material properties on proliferation and biosynthetic activity of chondrocytes as a function of time in culture.

\section{Biochemical Assay}

Cell proliferation during culture was analyzed by measuring the DNA content. Figure 2 shows the DNA content of constructs at varying culture time, week 1 to 4 . Cell proliferation, normalized to day 0 DNA values, showed a slight reduction in the first week. A similar observation has been reported for PEG hydrogels with smaller mesh sizes by Villanueva et al. (11). PEGDA-6 k and PEGDA-10 k having similar mesh sizes exhibited comparable DNA content at all time points. PEGDA-20 k constructs measured at week 4 showed the highest DNA content in the series, indicating a stronger correlation between network mesh size and cell proliferation.

We next evaluated the accumulation of cartilage-specific ECM components. Among hydrogels with varying network mesh sizes, PEGDA-6 k and $-10 \mathrm{k}$ showed similar GAG accumulation and had maximum GAG content at week 4
Fig. I SEM images of lyophilized PEG hydrogels where the hydrogels were synthesized from PEGDA precursors of varying molecular weight $(\mathbf{A}$ : PEGDA3.4 k, B: PEGDA-6 k, C: PEGDA$10 \mathrm{k}$ and D: PEGDA-20 k) (scale bar- $50 \mu \mathrm{m}$ ).

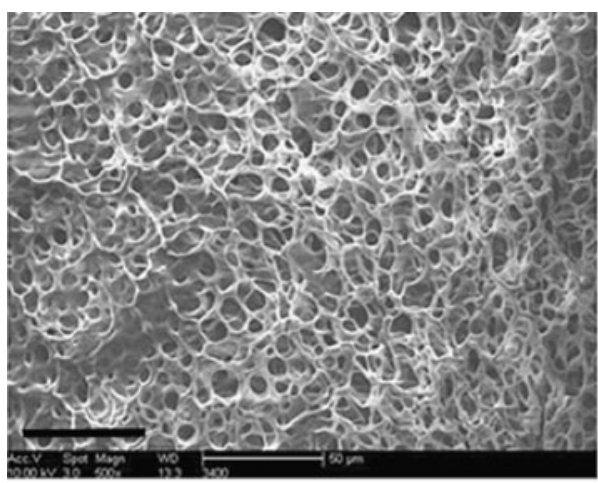

A

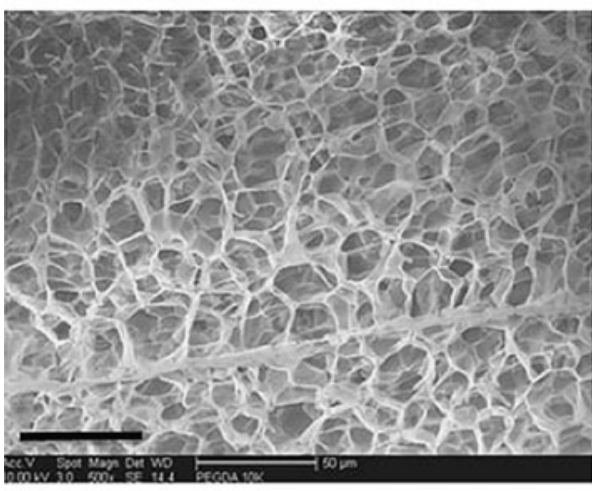

C

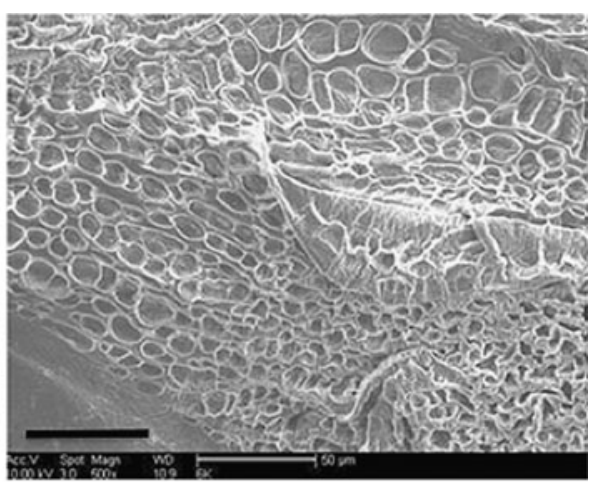

B

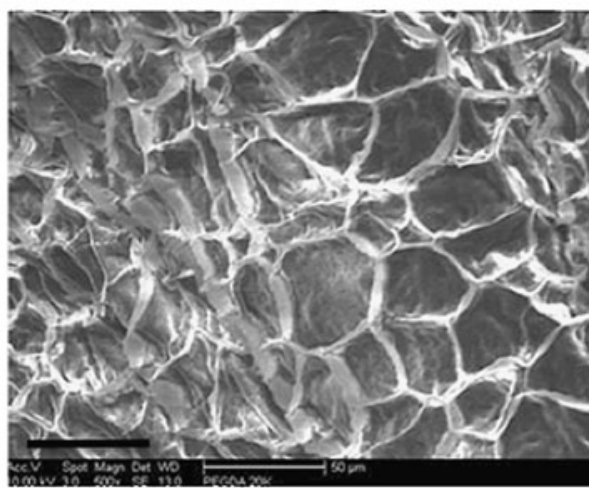

D 
Table 3 Mechanical Properties of PEGDA Hydrogels

\begin{tabular}{lccr}
\hline Hydrogel & $\begin{array}{l}\text { Compressive } \\
\text { modulus (kPa) }\end{array}$ & $\begin{array}{l}\text { Ultimate } \\
\text { strain (\%) }\end{array}$ & \multicolumn{1}{l}{$\begin{array}{l}\text { Ultimate } \\
\text { strength (kPa) }\end{array}$} \\
\hline PEGDA- 3.4 k & $64.4(4)$ & $36(3.8)$ & $53(8.2)$ \\
PEGDA- 6 k & $52(2.1)$ & $45(0.2)$ & $58(4.1)$ \\
PEGDA-10 k & $31(0.5)$ & $52(0.2)$ & $60(5.1)$ \\
PEGDA-20 k & I I (0.5) & $77(4.5)$ & $2,244($ I 24) \\
\hline
\end{tabular}

${ }^{a}$ Values in the parenthesis represent standard deviation.

Statistical analysis of compressive properties shows that only PEGDA-20 k was statistically different from the rest of the hydrogels.

(Fig. 3). Despite showing similar GAG content as that of PEGDA- $6 \mathrm{k}$ and $-10 \mathrm{k}$ at week 1, PEGDA-20 k hydrogels with a mesh size of $13 \mathrm{~nm}$ had a lower GAG content at week 4, very similar to that of PEGDA-3.4 k. Figure 4 shows the collagen content of the constructs normalized to the respective DNA content over time. Unlike GAG content, higher collagen content was observed in PEGDA$20 \mathrm{k}$, indicating that larger mesh size supports increased collagen accumulation.

\section{Gene Expression by Qrt-PCR}

Chondrocyte gene expression for cartilage specific markers was analyzed after four weeks of culture with respect to primary chondrocytes encapsulated in corresponding hydrogels by qRT-PCR. As shown in Fig. 5, collagen II and aggrecan expression were highest in PEGDA-10 k, while collagen I expression was highest in PEGDA-3.4 k. For all of the PEGDA hydrogels, collagen II expression was downregulated, while collagen I expression was upregulated (approximately 99-148-fold). Among all of the PEGDA hydrogels, PEGDA-10 k showed the greatest upregulation of collagen II (by 2-fold), while collagen I was downregulated.

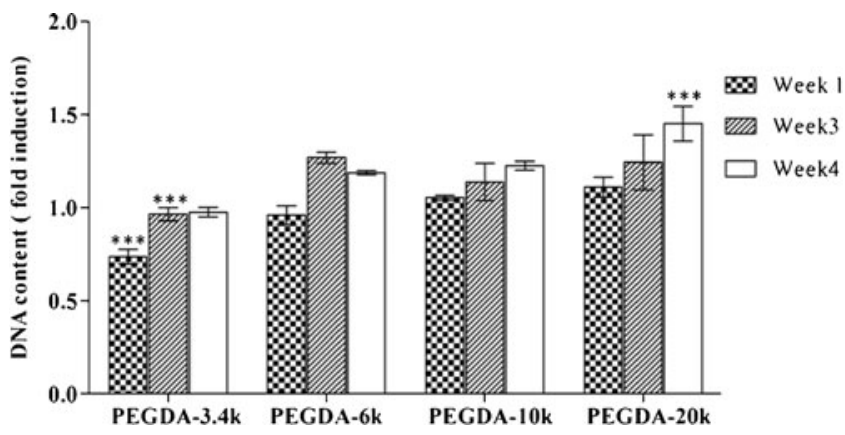

Fig. 2 Quantification of proliferation (DNA content) of chondrocytes in different PEG constructs (DNA normalized to corresponding day 0 values) as a function of culture time. Data points marked as $* * * *$ (with $p<0.00 \mathrm{I}$ ) are significantly different as compared to other data points at similar culture time.

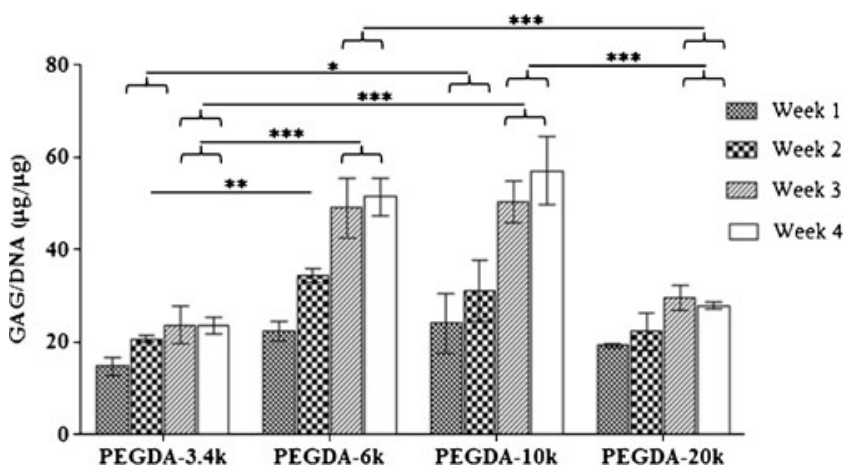

Fig. 3 Accumulation of glycosamino glycan components (normalized to corresponding DNA) in different PEG constructs at different time points. Statistically significant difference at corresponding time points are marked by $*$ for $p<0.05$, ** for $p<0.01$ and **** for $p<0.00$ I.

\section{Histological and Immunofluorescent Assays}

The extracellular matrix accumulation was also analyzed using histochemical and immunoflurorescent analysis. As seen from Fig. 6, Safranin-O staining for GAG after four weeks of culture showed more GAG in PEGDA-6 k and PEGDA-10 $\mathrm{k}$ as compared to that in PEGDA-3.4 k and PEGDA-20 k, supporting the trend observed in the biochemical assay. Figure 7 shows images of immunofluorescent staining of the constructs for collagen type II. With increase in the molecular weight of PEGDA precursor, collagen type II content per nuclei was observed to increase.

\section{DISCUSSION}

This study investigates the correlation of hydrogel mesh size with cellular activity of chondrocytes. The space provided by the polymer network can be a defined physical boundary for the cells and their secreted ECM components. Studies have shown that network mesh size could have a significant

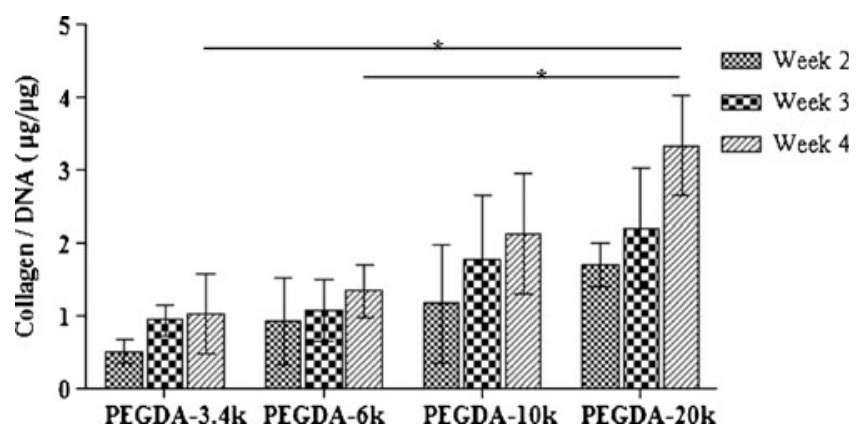

Fig. 4 Quantification of accumulation of collagen content (normalized to DNA) in different PEG constructs at various time points. Statistically significant difference at corresponding time points are marked by * for $p<0.05$. 
Fig. 5 Gene expression analysis

of cartilage specific markers $(\mathbf{A}$ :

Collagen I, B: Collagen II, C:

Aggrecan) for chondrocytes encapsulated in different PEG constructs at 4 weeks of culture, normalized to respective day 0 values. Statistically significant difference at corresponding time points are marked by * for $p<$ 0.05 , ** for $p<0.01$ and $* * *$ for $p<0.001$.
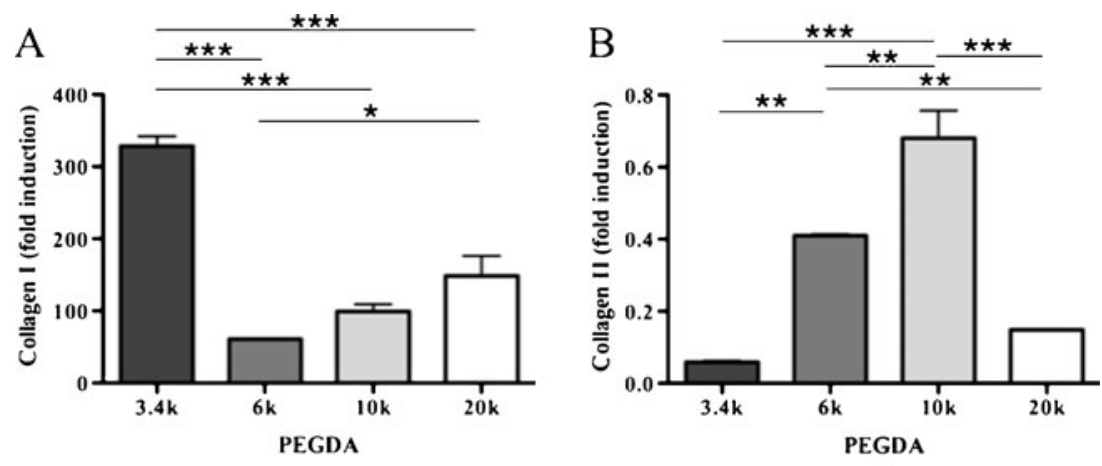

C

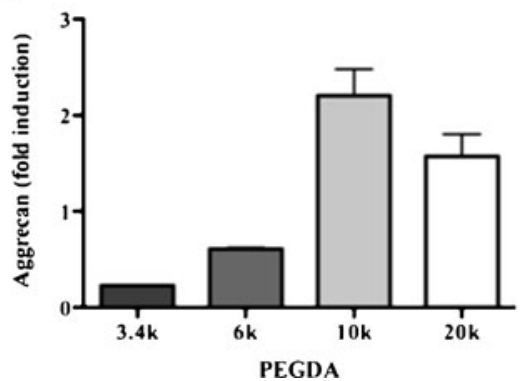

effect on the diffusion and distribution of cell-secreted ECM components (18). For example, a study by Bryant $e t$ al. has shown improved cartilaginous matrix deposition by encapsulated chondrocytes with increase in the mesh size of the hydrogel where the mesh size was manipulated by copolymerizing with degradable comonomer (25). Studies have also examined the effect of network mesh size coupled with culture conditions, static vs. dynamic, on cellular activities. Most studies focusing on examining the effect of network mesh size of hydrogels on cellular activities had modulated the crosslink density by varying precursor concentration or by using semi-interpenetrating network $(14,17,25)$. To our
Fig. 6 Images of Safranin-O staining of constructs after 4 weeks of culture (A: PEGDA3.4 k, B: PEGDA-6 k, C: PEGDA$10 \mathrm{k}$ and $\mathbf{D}$ : PEGDA-20 $\mathrm{k}$ ) (scale bar- $100 \mu \mathrm{m})$.
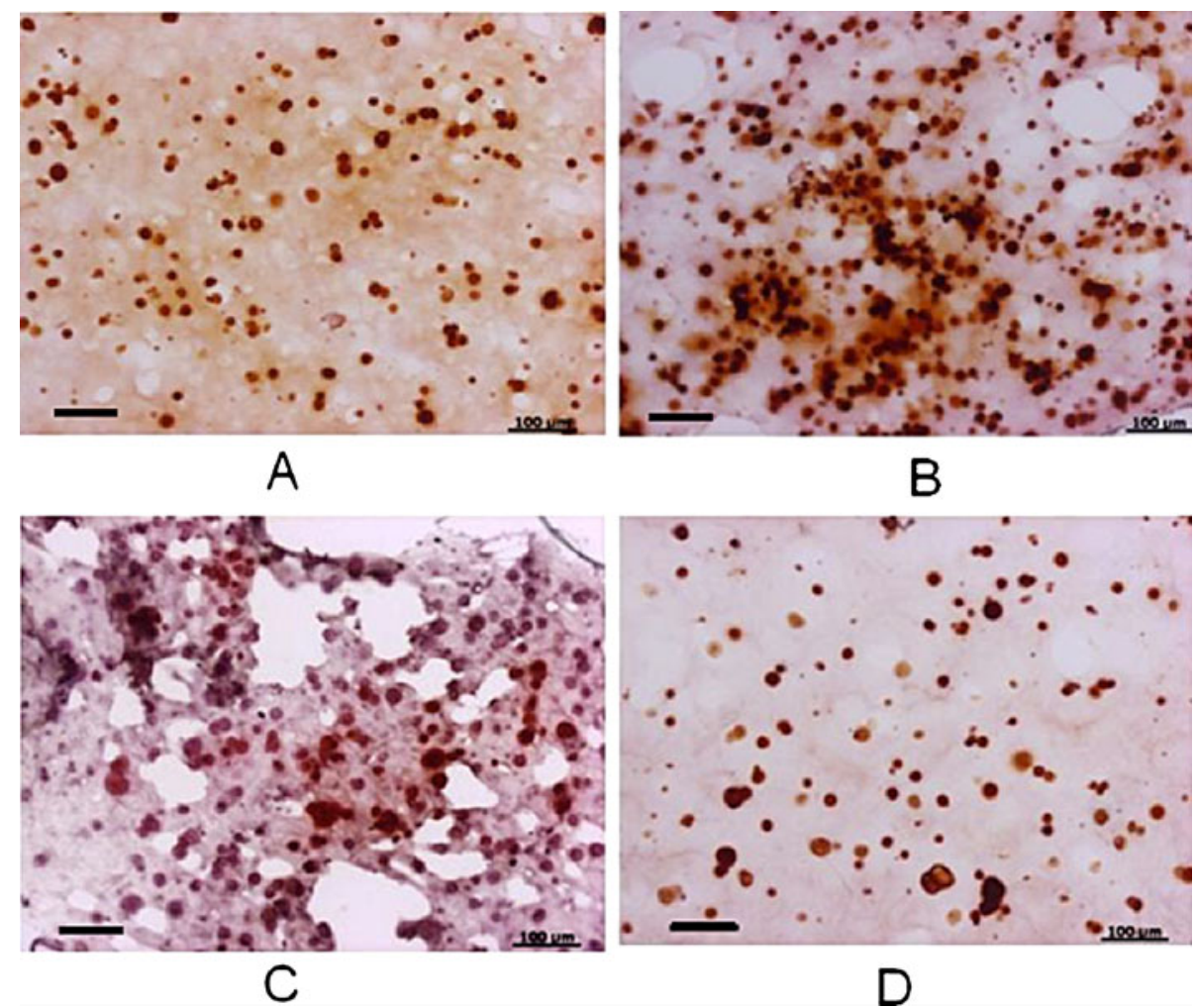
Fig. 7 Images of immunofluorescent staining of constructs for collagen type II after 4 weeks of culture (A: PEGDA-3.4 k, B: PEGDA-6 k, C: PEGDA- $10 \mathrm{k}$ and D: PEGDA-20 k) (scale bar$50 \mu \mathrm{m})$.

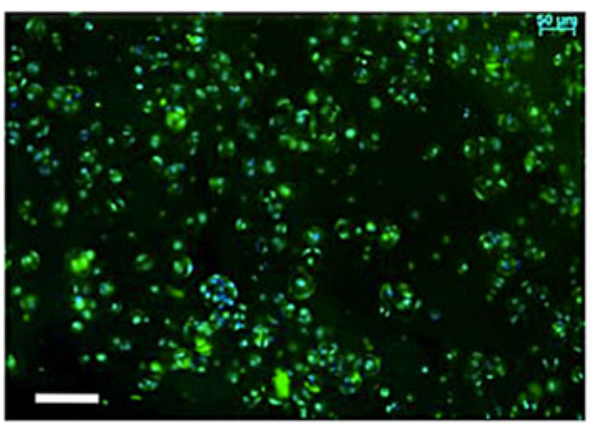

A

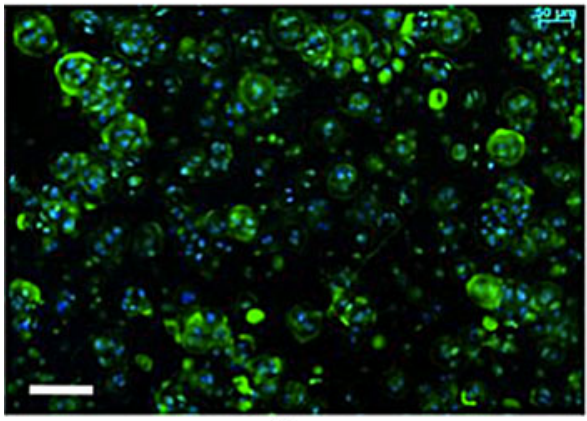

C

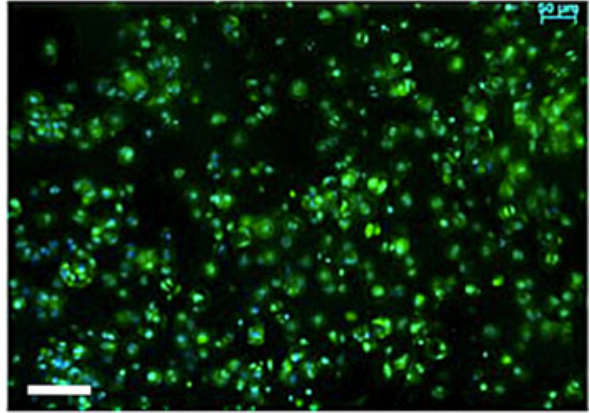

B

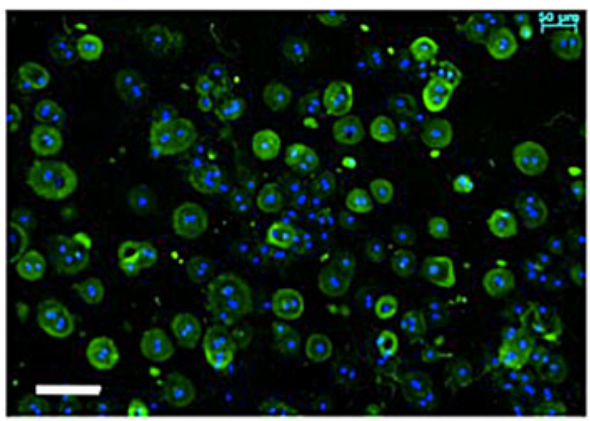

D knowledge, this is the first study wherein the sole effect of hydrogel network mesh size on the chondrocytes is evaluated by employing a single component precursor at a fixed concentration.

In addition to the mesh size, varying the molecular weight of the precursors affected the mechanical properties of the hydrogels. PEGDA-3.4 $\mathrm{k}$ hydrogels exhibited maximum compressive modulus, while PEGDA-20 k showed the highest ultimate strength. This is not surprising given that for precursors at a given concentration, molecular weight between the crosslinks $\left(\bar{M}_{c}\right)$ plays a significant role in determining their mechanical strength. Hydrogel networks with larger $\bar{M}_{c}$ usually exhibit low compressive modulus as compared to hydrogels with smaller $\bar{M}_{c}$ values (26), while $\bar{M}_{c}$ has an opposite effect on ultimate strength (i.e. higher stress is shown by hydrogels with larger $\bar{M}_{c}$ value). Therefore, there is a trade-off between compressive modulus and ultimate strength in a chemically crosslinked hydrogel network. Similarly for the same concentration of precursors $(10 \%)$, the equilibrium swelling ratios were directly proportional to the molecular weight of the precursors.

As seen from DNA analysis, chondrocytes in PEGDA$20 \mathrm{k}$ having a greater mesh size proliferated more compared to other hydrogels, while chondrocytes in PEGDA-6 k and PEGDA-10 k, having similar mesh size, exhibited comparable proliferation. However, the precursor molecular weight had a differential effect on matrix accumulation, where PEGDA-10 k and $-20 \mathrm{k}$ promoted collagen accumulation, while PEGDA-6 $\mathrm{k}$ and $-10 \mathrm{k}$ promoted GAG accumulation as seen from histochemical and biochemical analysis. The lower GAG content observed in PEGDA-20 $\mathrm{k}$ could be attributed to their larger mesh size, which may facilitate diffusion of smaller GAG molecules out of scaffold as compared to higher molecular weight collagen molecules (27). Previous studies showed the effect of network mesh size on the diffusion of GAG molecules (18). Furthermore, due to their high solubility in water, GAG can easily diffuse out of the gel prior to their polymerization into larger molecules $(28,29)$. However, small amount of GAG detected in culture medium $(\sim 5.94$ to $6.8 \mu \mathrm{g} / \mu \mathrm{g})$ suggests that the chondrocytes in PEGDA-20 k could be secreting less GAG as compared to PEGDA-6 k and $-10 \mathrm{k}$. The gene expression analysis of chondrocytes cultured on varying PEGDA hydrogels show higher aggrecan and collagen type II expression in PEGDA$10 \mathrm{k}$ while maintaining minimal upregulation of collagen type I. These findings suggest that the network structure of the hydrogels within which the chondrocytes are embedded could have a significant influence on their proliferation, maintenance of phenotype, and biosynthetic activity.

\section{CONCLUSION}

Hydrogels with varying structural and mechanical properties were created by using PEGDA precursors of varying molecular weights. Mesh size of the PEGDA hydrogels was 
found to influence the cellular response of chondrocytes in terms of their proliferation, gene expression, and accumulation of ECM. Increasing mesh size of the hydrogels resulted in the cell proliferation. However, the mesh size had a differential effect on ECM accumulation and gene expression of encapsulated chondrocytes.

\section{ACKNOWLEDGMENTS}

The authors thank YongSung Hwang for his help in SEM.

Open Access This article is distributed under the terms of the Creative Commons Attribution Noncommercial License which permits any noncommercial use, distribution, and reproduction in any medium, provided the original author(s) and source are credited.

\section{REFERENCES}

1. Elisseeff J, McIntosh W, Anseth K, Riley S, Ragan P, Langer R. Photoencapsulation of chondrocytes in poly(ethylene oxide)-based semi-interpenetrating networks. J Biomed Mat Res. 2000;51:16471.

2. Riley SL, Dutt SR, La Torre R, Chen AC, Sah RL, Ratcliffe A. Formulation of PEG-based hydrogels affects tissue-engineered cartilage construct characteristics. J Mater Sci: Materials in medicine. 2001;12:983-90.

3. Bryant SJ, Anseth K. The effects of scaffold thickness on tissue engineered cartilage in photocrosslinked poly(ethylene oxide) hydrogel. Biomaterials. 2001;22:619-26.

4. Liu SQ Tay R, Khan M, Ee PLR, Hedrick JL, Yang YY. Synthetic hydrogels for controlled stem cell differentiation. Soft Matter. 2010;6:67-81.

5. Kraehenbuehl TP, Ferreira LS, Zammaretti P, Hubbell JA, Langer R. Cell-responsive hydrogel for encapsulation of vascular cells. Biomaterials. 2009;30:4318-24.

6. Kloxin AM, Kasko AM, Salinas CN, Anseth K. Photodegradable hydrogel for dynamic tuning of physical and chemical properties. Science. 2009;324:59-63.

7. Banerjee A, Arha M, Choudhary S, Ashton RS, Bhatia SR, Schaffer DV, et al. The influence of hydrogel modulus on the proliferation and differentiation of encapsulated neural stem cells. Biomaterials. 2009;30:4695-9.

8. Bryant S, Arthur J, Anseth K. Incorporation of tissue-specific molecules alters chondrocyte metabolism and gene expression in photocrosslinked hydrogels. Acta Biomater. 2004;1:243-52.

9. Ferdinand A, Florian S, Achim G. Rationale design of hydrogels for tissue engineering: impact of physical factors on cell behavior. Biomaterials. 2007;28:134-46.

10. Peyton SR, Raub CB, Keschrumrus VP, Putnam AJ. The use of poly(ethylene glycol) hydrogels to investigate the impact of ECM chemistry and mechanics on smooth muscle cells. Biomaterials. 2009;27:4881-93.

11. Villanueva I, Klement BJ, Deutsch D, Bryant SJ. Cross-linking density alters early metabolic activities in chondrocytes encapsulated in poly(ethylene glycol) hydrogels and cultured in the rotating wall vessel. Biotechnol Bioeng. 2009;102:124250 .
12. Hwang NS, Varghese S, Lee HJ, Therprungsirilul P, Canver A, Sharma B, et al. Response of zonal chondrocytes to extracellular matrix hydrogels. FEBS Lett. 2007;581:4172-8.

13. Lein S-M, Ko L-Y, Huang T-J. Effect of pore size on ECM secretion and cell growth in gelatin scaffold for articular cartilage tissue engineering. Acta Biomater. 2009;5:670-9.

14. Bryant SJ, Chowdhury TT, Lee DA, Bader DL, Anseth KS. Crosslinking density influences chondrocyte metabolism in dynamically loaded photocrosslinked poly(ethylene glycol) hydrogels. Annal Biomed Eng. 2004;32:407-17.

15. Bryant SJ, Anseth KS, Lee DA, Bader DL. Crosslinking density influences the morphology of chondrocytes photoencapsulated in PEG hydrogels during the application of compressive strain. J Orth Res. 2004;22:1143-9.

16. Buxton AN, Zhu J, Marchant R, West JL, Yoo JU, Johnstone B. Design and characterization of poly(ethylene glycol) photopolymerizable semi-interpenetrating networks for chondrogenesis of human mesenchymal stem cells. Tissue Eng. 2007;13:2549-60.

17. Chung C, Mesa J, Randolph MA, Yaremchuk M, Burdick JA. Influence of gel properties on neocartilage formation by auricular chondrocytes photoencapsulated in hyaluronic acid networks. J Biomed Mat Res Part A. 2007;77:518-25.

18. Bryant SJ, Anseth KS. Hydrogel properties influence ECM production by chondrocytes encapsulated in poly(ethylene glycol) hydrogels. J Biomed Mater Res. 2002;59:63-72.

19. Zhang C, Aung A, Liao L, Varghese S. A novel single precursorbased biodegradable hydrogel with enhanced mechanical properties. Soft Matter. 2009;5:3831-4.

20. Slaughter BV, Khurshid SS, Fisher OZ, Khademhosseini A, Peppas NA. Hydrogels in regenerative medicine. Adv Mater. 2009;21:3307-29.

21. Hwang NS, Varghese S, Zhang Z, Elisseeff J. Chondrogenic differentiation of human embryonic stem cell-derived cells in arginine-glycine-aspartate-modified hydrogels. Tissue Eng. 2006;12:2695-706.

22. Farndale RW, Buttle DJ, Barrett AJ. Improved quantitation and discrimination of sulphated glycosaminoglycans by use of dimethylmethylene blue. Biochim Biophy Acta. 1986;883:173-7.

23. Hwang NS, Varghese S, Elisseeff J. In editor: Yemuri MC. Directed differentiation of embryonic stem cells in threedimensional hydrogel culture, Methods Mol. Bio. 407, Humana Press: NJ; 2007, p351-373.

24. Venn M, Maroudas A. Chemical composition and swelling of normal and osteoarthritic femoral head cartilage. I Chemical composition Ann Rheum Dis. 1977;36:121-9.

25. Bryant SJ, Durand KL, Anseth KS. Manipulations in hydrogel chemistry control photoencapsulated chondrocyte behavior and their extracellular matrix production. J Biomed Mater Res Part A. 2003;67:1430-6.

26. Houwink R, De Decker HK. Elasticity, plasticity and structure of matter. 3rd ed. Cambridge: Cambridge University Press; 1971. Chapter 9.

27. Hwang YS, Sangaj NS, Varghese S. Interconnected macroporous poly(Ethylene Glycol) cryogels as a cell scaffold for cartilage tissue engineering. Tissue Eng Part A. 2010;16:3033-41.

28. Mahmood TA, Shastri VP, van Blitterswijk CA, Langer R, Riesle J. Tissue engineering of bovine articular cartilage within porous poly(ether ester) copolymer scaffolds with different structures. Tissue Eng. 2005;11:1244-53.

29. van Susante JLC, Pieper J, Buma P, van Kuppevelt TH, van Beuningen $\mathrm{H}$, van der Kraan PM, et al. Linkage of chondroitin-sulfate to type I collagen scaffolds stimulates the bioactivity of seeded chondrocytes in vitro. Biomaterials. 2001;22:2359-69. 